\title{
BMJ Open Uneven state distribution of homicides in Brazil and their effect on life expectancy, 2000-2015: a cross-sectional mortality study
}

\author{
José Manuel Aburto (D) , , Julia Calazans, ${ }^{3}$ Bernardo Lanza Queiroz (D) , ${ }^{3}$ \\ Shammi Luhar, ${ }^{4}$ Vladimir Canudas-Romo (D) ${ }^{5}$
}

To cite: Aburto JM, Calazans J,

Lanza Queiroz B, et al. Uneven state distribution of homicides in Brazil and their effect on life expectancy, 2000-2015: a cross-sectional mortality study. BMJ Open 2021;11:e044706. doi:10.1136/ bmjopen-2020-044706

- Prepublication history and supplemental material for this paper is available online. To view these files, please visit the journal online (http://dx.doi. org/10.1136/bmjopen-2020044706).

Received 10 September 2020 Revised 08 January 2021 Accepted 28 January 2021

\section{Check for updates}

(c) Author(s) (or their employer(s)) 2021. Re-use permitted under CC BY-NC. No commercial re-use. See rights and permissions. Published by BMJ.

For numbered affiliations see end of article.

\section{Correspondence to} Dr José Manuel Aburto; jose-manuel.aburto@sociology. ox.ac.uk

\section{ABSTRACT}

Objective To determine cause-specific and age-specific contributions to life expectancy changes between 2000 and 2015, separately by state and sex in Brazil, with a focus on homicides.

Design Retrospective cross-sectional demographic analysis of mortality.

Setting and population Brazilian population by age, sex and state from 2000 to 2015.

Main outcome measure Using mortality data from the Brazilian Mortality Information System and population estimates from the National Statistics Office, we used death distribution methods and the linear integral decomposition model to estimate levels and changes in life expectancy. We also examine how multiple causes of death, including those attributable to homicides and amenable/avoidable mortality, contributed to these changes from 2000 to 2015.

Results Between 2000 and 2015, life expectancy in Brazil increased from 71.5 to 75.1 years. Despite statelevel variation in gains, life expectancy increased in almost all states over this period. However across Brazil, homicide mortality contributed, to varying degrees, to either attenuated or decreased male life expectancy gains. In Alagoas in 2000-2007 and Sergipe in 2007-2015, homicides contributed to a reduction in life expectancy of 1.5 years, offsetting gains achieved through improvements due to medically amenable causes. In the period 20072015, male life expectancy could have been improved by more than half a year in 12 of Brazil's states if homicide mortality had remained at the levels of 2007.

Conclusions Homicide mortality appears to offset life expectancy gains made through recent improvements to mortality amenable to medical services and public health interventions, with considerable subnational heterogeneity in the extent of this phenomenon. Efforts combating the causes of homicides can increase life expectancy beyond what has been achieved in recent decades.

\section{INTRODUCTION}

Violence and homicides in Brazil present a considerable public health challenge. ${ }^{1}$ With a risk of mortality from homicides 10 times that of most developed countries and it being the leading cause of death among young
Strengths and limitations of this study

- We examine data from the Mortality Information System and from the National Statistics office from Brazil.

- We employed death distribution methods in order to correct for the lack of completeness towards the beginning of the study period.

- We use the concept of amenable/avoidable mortality to form the basis of the cause of death classifications in our study to complement the analysis of homicide mortality.

adults, ${ }^{2} 3$ recent improvements in population health attributable to ongoing public health interventions and pushes towards universal health coverage are in jeopardy. ${ }^{4-7}$ On average, Brazilians live 20 years longer than half a century ago. ${ }^{8}$ These mortality advancements have been driven largely by improvements in medically amenable mortality, in particular infant and cardiovascular disease mortality, which have accompanied the introduction and expansion of a mandated universal healthcare system. ${ }^{9} 10$

Country-level estimates of life expectancy, estimated at 74.7 years in 2015 , mask considerable subnational heterogeneity. For instance, life expectancy in 2000 ranged from 63.2 years in Alagoas to 71.3 years in Santa Catarina (online supplemental figure 1 presents a map of Brazil and its states). In addition, women tend to have higher life expectancy than men in Brazil (78.7 and 71.6, respectively in 2015) and homicide rates among men are approximately 10 times higher. ${ }^{11}$ Gains in life expectancy have also varied considerably across the country, driven in part by differential gains in average lifespan attributable to amenable mortality; improvements have ranged between 0.6 and 4.1 years between Brazil's Southeast and Northeast 
regions, respectively, between 2000 and $2010 .{ }^{12}$ The high mortality risk from homicides has the potential to reverse gains in life expectancy, as has been reported in Brazil ${ }^{13}$ and other Latin American countries. ${ }^{1}$ Despite this, the effect of homicides on changes to life expectancy has not been explored in the Brazilian context at the state level in recent periods of time, despite it being a country with over 60000 murders reported in 2018. ${ }^{14}$ An explanation for the lack of studies investigating this could be that national statistics do not report notable changes in homicide rates in the past decade, however this could be due to the balancing effect of homicide rates simultaneously increasing in some states while decreasing in others. For example, whereas the homicide rate declined in Brasilia between 2007 and 2011, in the same period, homicides have increased by more than $40 \%$ in Bahia. ${ }^{14}$

In this study, we aim to examine causes of death considered avoidable/amenable to medical service, with a focus on homicide mortality, and their impact on changes in life expectancy by state for men and women separately in the period 2000-2015. These results will provide information for interventions and planning aimed at reducing the burden of homicides. Specifically, they will communicate potential improvements to life expectancy gains that could be achieved through reducing homicide mortality, in addition to identifying the states in most need of public policy attention to minimise these violence and health disparities.

\section{METHODS}

We extracted state-level mortality data by age, sex, year and cause of death from the Mortality Information System produced by the Brazilian Ministry of Health. ${ }^{15}$ We obtained state-level population estimates for the years 2000 through 2015 from the National Statistics Office. ${ }^{16}$

Death counts registration was evaluated across states in Brazil with traditional demographic methods known as death distribution methods, ${ }^{17}{ }^{18}$ since there is evidence of under-reporting of death counts and variation in data quality across regions. ${ }^{19}$ Over the study period (20002015 ), death counts registration improved to over $90 \%$ completeness. ${ }^{20}$ The method is based on population dynamics equations and assesses the coverage of deaths in relation to the population and the quality of the declaration of death information. Whenever necessary, the methods provide an adjustment factor that is used to correct death counts registration in each region and obtain an appropriately adjusted estimate of mortality (see online supplemental appendix 1). These methods are commonly used by the United Nations and the Institute of Health Metrics and Evaluation and in several national statistics offices.

\section{Cause of death classification}

We use the concept of amenable/avoidable mortality to form the basis of the cause of death classifications in our study to complement the analysis of homicide mortality.
Deaths without information on age at death were distributed proportionally by the observed age profile. The concept of amenable/avoidable mortality refers to deaths that should be absent if both timely and quality healthcare is available below age 75 years. ${ }^{21}$ This concept has been successfully employed to link the progress of primary care expansion and reductions in amenable/ avoidable mortality in Brazil. ${ }^{9}$ More recently the concept has included causes amenable to public health interventions that have been seen to alter health behaviours, for example, lung cancer via smoking reduction or homicides.

Using a cause of death classification system used in similar studies, ${ }^{22}{ }^{23}$ we grouped the causes of death into the following 10 categories based on the International Classification of Diseases 10th revision (ICD-10) (online supplemental table 1): (1) homicides, (2) alcoholic liver disease, (3) diabetes, (4) HIV/AIDS, (5) ischaemic heart diseases (IHD), (6) lung cancer, (7) road traffic accidents, (8) suicides, (9) amenable to medical service (including conditions that could be reduced by primary care, secondary intervention and timely medical care up to age 75 years), and (10) all other causes (residual causes).

Homicides, liver disease, diabetes, HIV/AIDS, IHD, lung cancer and suicide were analysed separately as they are amenable to both health behaviours and medical attention, and pose important public health challenges in Brazil. ${ }^{24}{ }^{25}$ For instance, in 2001 Brazil featured in the top 10 countries ranked by number of suicide deaths. ${ }^{26}$ The category capturing causes amenable to medical services (9) is linked to major healthcare interventions that have been implemented in recent decades in Brazil, including the Family Health Program. ${ }^{9} 1027$

\section{Demographic methods}

We calculated age-specific and sex-specific death rates for 5 -year age groups with an open-age interval at age 90 years for Brazil's 27 states, and constructed sex-specific period life tables for each year from 2000 to 2015 following standard procedures. ${ }^{28}$ National results did not significantly differ from those reported by the United Nations. ${ }^{8}$ We calculated age-specific and cause-specific contributions to differences in life expectancy at birth following our classification for each subsequent year using the linear integral decomposition procedure (see online supplemental appendix 2 for detailed explanation) $)^{29}$ and summed up single-year decompositions in order to obtain the aggregate effect for the specified period. We report results for the periods 2000-2007 and 2007-2015 to have two comparable points in time of the same length. Our estimates refer to the middle of the year, for example, 2000-2007 runs from middle of 2000 to middle of 2007 and 20072015 runs from middle of 2007 to middle of 2015. The effects for the period 2000-2015 are simply the sum of the effects of the two periods. All procedures were performed using the R software ${ }^{30}$ and are fully reproducible from the 


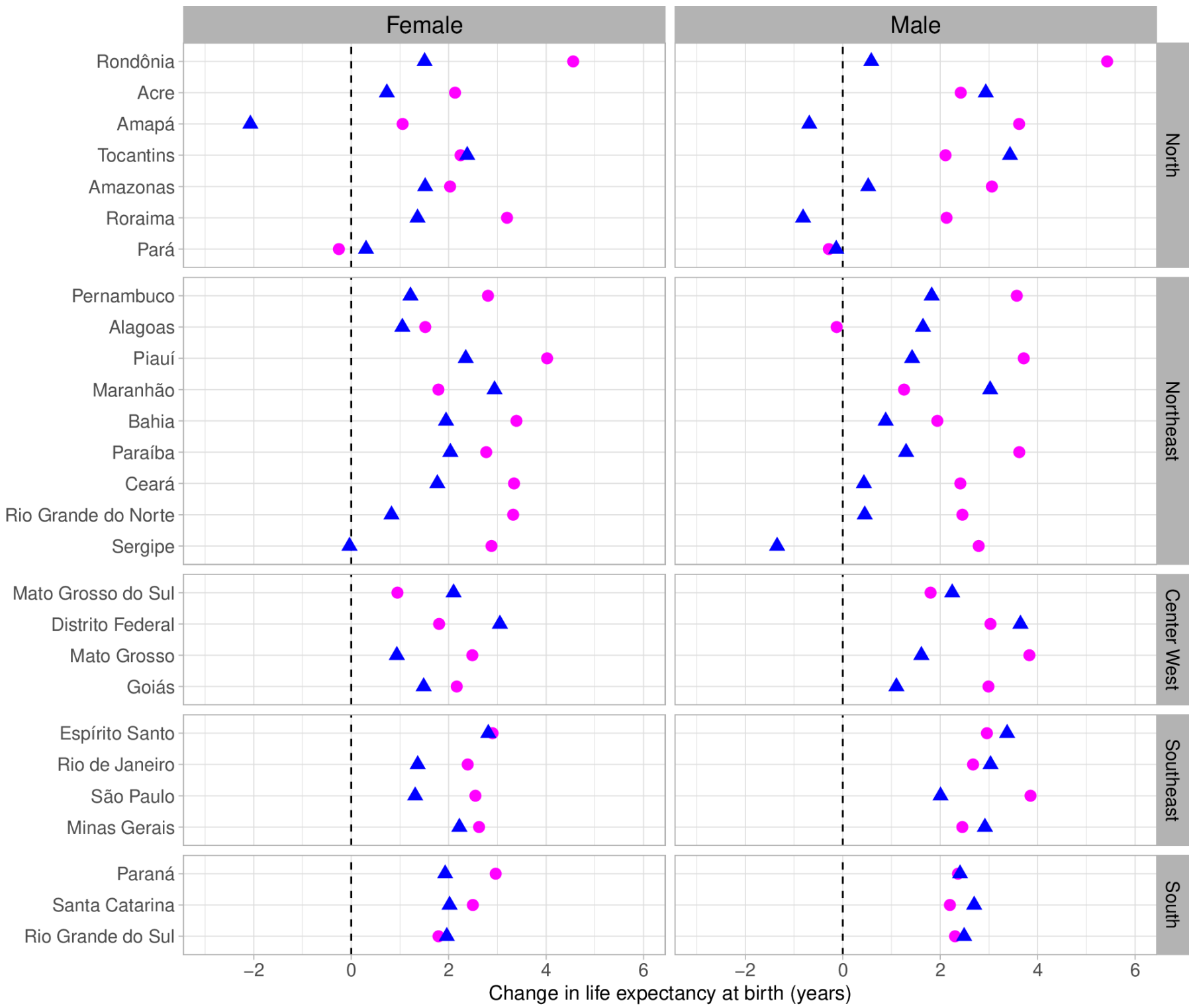

Period - 2000-07 A 2007-15

Figure 1 Changes in life expectancy at birth in Brazil (in years), by state and period, from 2000 to 2007 (pink dots) and from 2007 to 2015 (blue triangles). The dashed line at zero represents the situation of no changes in life expectancy over time, whereas dots and triangles to the right (left) of this line correspond to increases (decreases) in life expectancy.

public repository with the data needed at https://github. com/jmaburto/Homicides-and-life-expectancy-in-Brazil.

\section{Patient and public involvement}

This study involved secondary data analysis of public sources, thus patients and or the public were not involved in it.

\section{RESULTS}

We grouped the Brazilian states within each broad region, and subsequently arranged them in order of the impact of homicides on male life expectancy in 2007-2015 in figures 1-4.

All states, with the exception of Pará, experienced increases in life expectancy for women and men from
2000 to 2007 (figure 1). Relative to the period 20002007, in 2007-2015, life expectancy at birth increased at a slower pace among women in $75 \%$ of states and among men in $60 \%$ of Brazil's states. In four states, life expectancy at birth declined in the latter period among men; among women, life expectancy declined in one state. Despite this overall slowdown, all but four states (Amapá for women, and Amapá, Roraima, Pará and Sergipe for men) showed a continuous increase in life expectancy since 2000. Life expectancy levels for each state and total changes in 2000-2015 are shown in online supplemental table 2.

Figures 2-4 show how homicides, IHD and causes amenable to medical service, respectively, contributed to changes in life expectancy at birth in the periods 


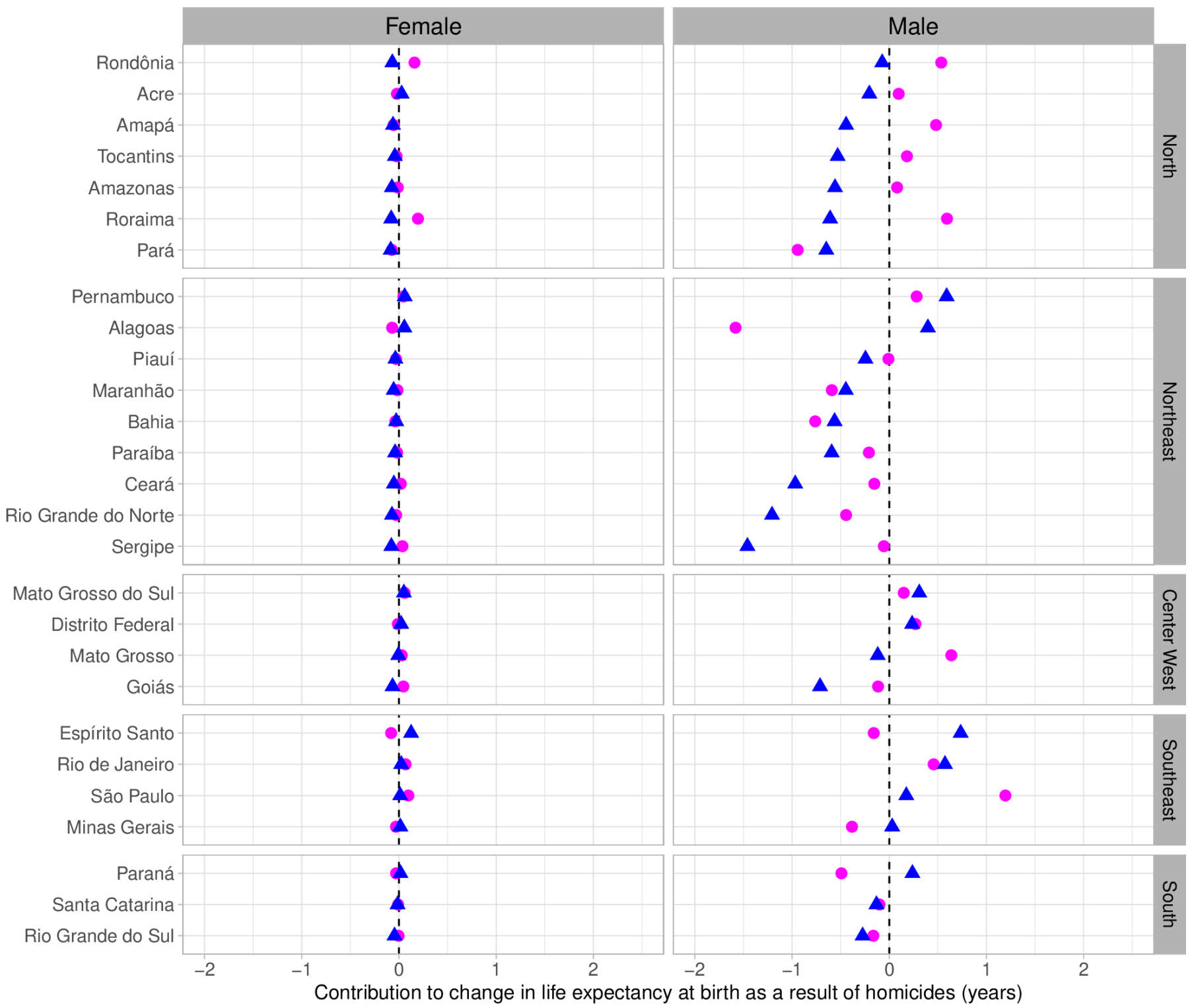

Period $\bullet 2000-07 \quad \Delta \quad 2007-15$

Figure 2 Contribution of homicides to changes in life expectancy at birth in Brazil (in years), by state and period, from 2000 to 2007 (pink dots) and from 2007 to 2015 (blue triangles). The dashed line at zero represents the situation of no contribution to changes in life expectancy over time, whereas dots and triangles to the right (left) of this line correspond to increases (decreases) in life expectancy due to changes in homicides.

2000-2007 and 2007-2015 and represent the causes of death from the amenable/avoidable mortality framework that contributed the most to changes in life expectancy at birth in both periods (results for all causes of death, see online supplemental figures 2 and 3 ).

Homicide mortality increased in 14 states among men in 2000-2007 (figure 2), leading to declines in life expectancy at birth over the period, with especially large contributions in Alagoas state (1.5 years). In 2007-2015 there was a clear worsening in life expectancy in 18 of Brazil's states related to increases in homicide mortality, with three of these states losing one or more years of life expectancy at birth, and 11 losing over 6 months of life on average. Overall, changes in mortality due to homicide were responsible for the largest declines in life expectancy between 2000 and 2015, compared with other causes. Over the 16-year period, the decline was most marked in the least developed Northeast and Northern regions of Brazil (online supplemental figure 4), including the states of Sergipe, Rio Grande do Norte, Ceará and Pará. The impact of homicides on life expectancy appeared to be restricted to men. As a sensitivity check in online supplemental figure 5, we show results for the periods 2000-2005, 2005-2010, 2010-2015. By breaking the study period into three-time segments it becomes clear that violence dynamics are changing continuously, and that they vary between states and regions. The largest losses in life expectancy were suffered in the last 10 years. 


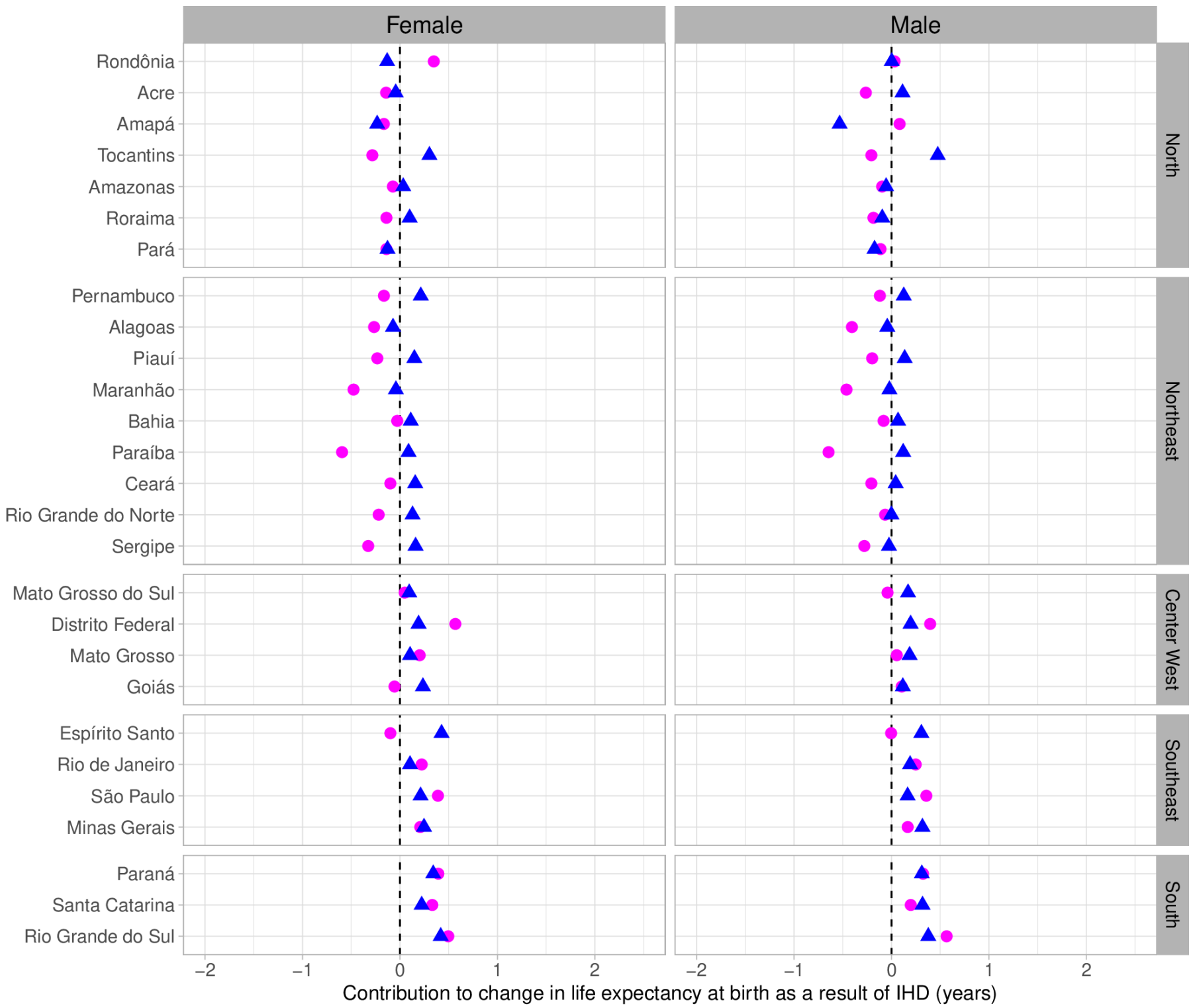

Period $-2000-07 \quad \Delta \quad 2007-15$

Figure 3 Contribution of ischaemic heart diseases (IHD) to changes in life expectancy at birth in Brazil (in years), by state and period, from 2000 to 2007 (pink dots) and from 2007 to 2015 (blue triangles). The dashed line at zero represents the situation of no contribution to changes in life expectancy over time, whereas dots and triangles to the right (left) of this line correspond to increases (decreases) in life expectancy due to changes in IHD.

Among women and men, 16 states and 15 states, respectively, experienced increases in mortality from IHD in the period 2000-2007, leading to declines in life expectancy.

On the other hand, in 2007-2015 life expectancy due to IHD increased in most states driven by improvements in cause-specific mortality from IHD (21 and 19 states, respectively, among women and men).

Across most states, we found increases in life expectancy due to causes amenable to medical services below age 75 years in both periods. In two states (Acre and Maranhão) we found declines in female life expectancy, while negligible effects on male life expectancy was found in Maranhão state in the period 2000-2007 (figure 4). Notably, between 2000 and 2007, 13 states experienced increases in female life expectancy of more than 1 year due to medically amenable mortality, whereas this was the case in 12 states among men. Between 2007 and 2015, mortality improvements due to medically amenable causes persisted, although at a slower pace, whereby 18 and 23 states experienced an increased life expectancy by more than 6 months among women and men, respectively, driven by declines in mortality from causes amenable to medical services. Similarly, changes in mortality due to the remaining causes also contributed to increasing life expectancy in most states during the first 15 years of the 21st century (see online supplemental figures 2 and 3 ).

Although diabetes mortality had a smaller impact on changes in life expectancy relative to other causes of 


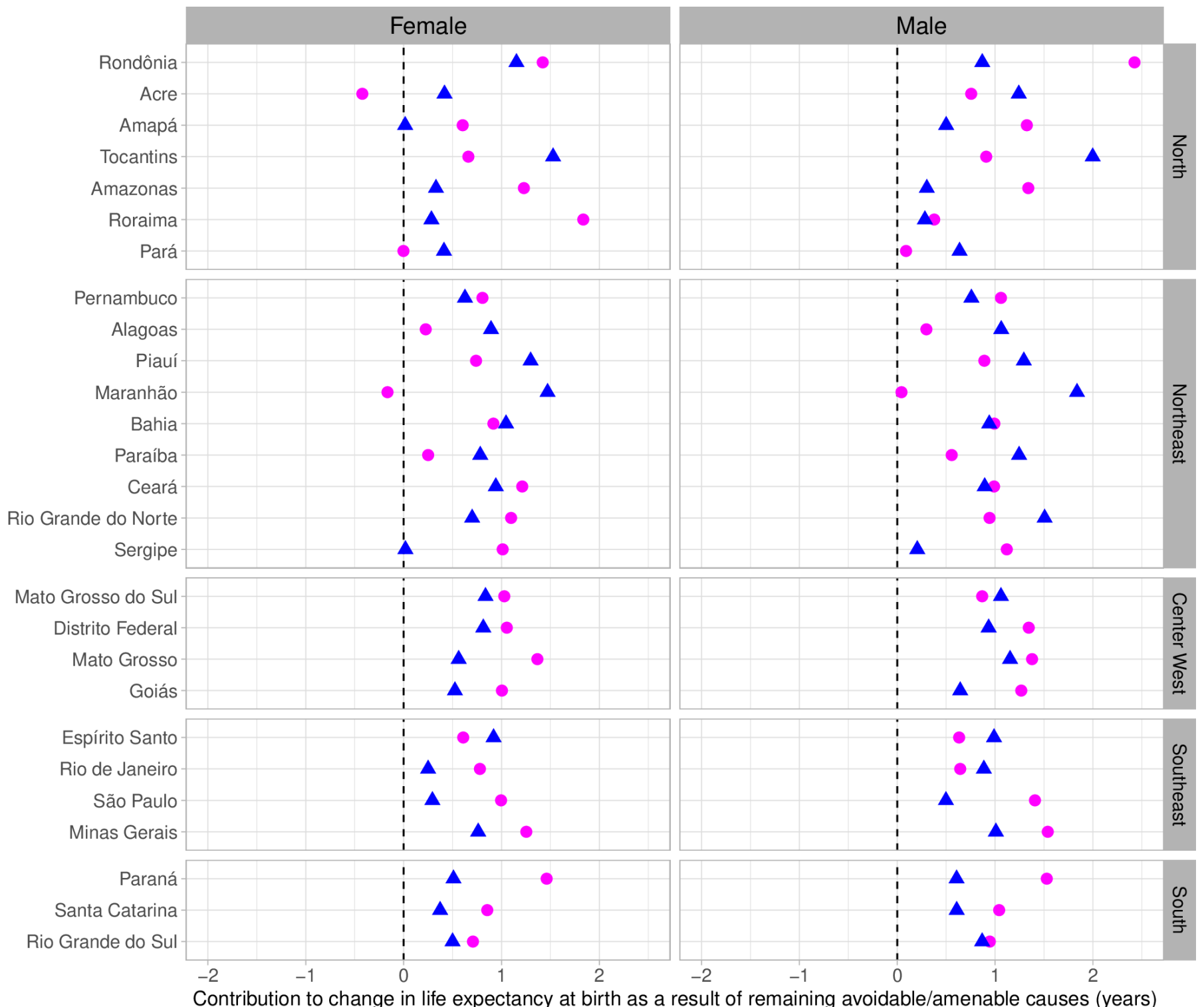

Contribution to change in life expectancy at birth as a result of remaining avoidable/amenable causes (years)

Period - 2000-07 A 2007-15

Figure 4 Contribution of causes amenable to medical service to changes in life expectancy at birth in Brazil (in years), by state and period, from 2000 to 2007 (pink dots) and from 2007 to 2015 (blue triangles). The dashed line at zero represents the situation of no contribution to changes in life expectancy over time, whereas dots and triangles to the right (left) of this line correspond to increases (decreases) in life expectancy due to changes in causes amenable to medical service.

death between 2000 and 2015, its impact was considerable in some regions. In the North and Northeast regions, the increase in diabetes mortality led to small decreases in life expectancy between 2000 and 2007, especially among women (online supplemental figure 3 ). This trend reversed and by 2007-2015, only three states from the Northern region (Amapá, Amazonas and Pará) experienced decreases in female life expectancy. Among men, the impact of diabetes was smaller, however similar to women, was concentrated in the Northern regions of Brazil (online supplemental figure 2).

Contributions to changes in life expectancy due to alcoholic liver disease, HIV/AIDS, lung cancer, suicide and traffic accidents were negligible between 2000 and 2015 (online supplemental figures 2 and 3).

\section{DISCUSSION}

The period from 2000 to 2015 marked an increase in the life expectancy at birth in Brazil from 71.5 years to 75.1 years, however the extent of this increase differed between men and women and between Brazil's diverse states. Our findings indicate that potentially large gains in state-specific life expectancy driven by mortality improvements from medically amenable causes were partially offset, at times, by increasing homicide, diabetes and IHD mortality. Brazilian men in 
particular have experienced a disproportionately higher homicide burden when compared with women. ${ }^{11}$ Had homicide mortality stayed at the same level as at the turn of the century in Brazil's Northern regions, male life expectancy could have increased by at least 6 months in 11 states during the period 2007-2015.

\section{Violence in Brazil}

Homicides are unevenly distributed across Brazil's states, leading to slower increases, and in some cases decreases, in male life expectancy. In some instances, increases in homicide mortality have been so drastic that it has driven declines in life expectancy by over 1year in seven states from the Northeast and North regions (Ceará, Alagoas, Rio Grande do Norte, Bahia, Maranhão, Sergipe and Pará). These states contain eight of the most dangerous cities in the world (Natal, Fortaleza, Belém, Feirá de Santana, Marceió, Vitória de Conquista, Salvador and Aracaju) with homicide rates over 47 deaths per 100000 people. ${ }^{31}$

Homicides in Brazil are primarily committed with firearms and are related to both drug trafficking, and consumption of drugs and alcohol. ${ }^{32}$ Evidence from Brazil suggests that gun control measures can be effective in reducing the burden of violence on population health through specific legislations aiming at firearm disarmament. ${ }^{33}$ While we find that such legislations have been effective in some states, in others, particularly in the North and Northeast of Brazil, further state-level efforts aimed at disarmament are encouraged, however the implementation of firearm regulations might be more challenging in these regions. ${ }^{33}$ Moreover, the Brazilian government has implemented several measures aiming at reducing violence in the country, such as the National Public Security Force (Força Nacional de Segurança Pública) and the National Public Security Program (Programa Nacional de Segurança Pública com Cidadania). ${ }^{3}$ However, there is considerable regional diversity in the success of these government strategies. The most relevant example to this study is the diversity in changes to life expectancy driven by homicide mortality post-strategy implementation, which started in 2004, in the period 2007-2015, with declines in homicide-related life expectancy most prevalent in the North and Northeast (complementary figure from 2004 is shown in online supplemental figure 6).

Evidence suggests that violent death varies considerably by ethnicity, whereby black and ethnically mixed men are at a higher risk of being victims of violent crime. ${ }^{34}{ }^{35}$ In 2007 , $55 \%$ of the total homicides among men were among mixed race individuals, while $8.2 \%$ were among black men. Poverty, social inequality and drug trafficking are important factors determining variation in violent mortality within Brazil's states. ${ }^{36-38}$ For example, homicides have increased in regions undergoing an accelerated urbanisation process coupled with slow and unequal economic development. ${ }^{39}$ Factors such as poverty, exclusion, and lack of opportunities and safety may encourage violent behaviours. In certain regions, this may lead young people, especially men, to turn to crime as a profitable and economically attractive option, ${ }^{39}$ potentially explaining the increase in violence in some states. In this study, we were unable to disentangle the effect of changes in homicide mortality on life expectancy changes by ethnicity or socioeconomic status within states due to the lack of data disaggregated by these levels for long periods of time.

\section{International context with Latin America}

Latin America is currently the region with the highest homicide rates globally. ${ }^{14}$ As in Brazil, similar detrimental findings of the effect of violence in life expectancy have been reported in other Latin American contexts. ${ }^{1}$ In Mexico, the rise in homicides has led to a stagnation in country-wide life expectancy between 2000 and 2010, ${ }^{4041}$ with significant subnational variation, ${ }^{22}$ and was identified as a primary determinant of lifespan inequalities. ${ }^{42}$ Another study in Venezuela found that an increase in firearm-related deaths led to life expectancy stagnation in 1996-2013. ${ }^{43}$ In Colombia, although homicides have decreased over the last decade, they still represent a large share of total mortality (around 5\%), which is estimated to cause a loss of life expectancy of 2.2 and 0.2 years for men and women, respectively. ${ }^{44}$ Similar evidence from Brazil at the national level showed that life expectancy could improve 1.5 years for men if homicides were eliminated. ${ }^{45}$ Other studies report evidence of further adverse impacts of violence on population health beyond mortality and decreases in life expectancy. For example, mental health and perception of vulnerability in contexts of increasing homicide mortality are often unquantifiable. ${ }^{46}$ Consequently, health systems should be prepared for a future increase in mental health issues due to potential insecurity felt by Brazilians. In light of this, further studies into the population health burden of homicides, beyond just mortality, across Brazil's states are encouraged.

\section{Other causes of death}

The period 2000-2007 also saw increases in mortality from IHD, again offsetting rising life expectancy due to improvements in mortality from other medically amenable causes, and again mostly concentrated in Brazil's Northern states. Additionally, some Northern states saw increases in diabetes mortality over the same period, primarily affecting women. On the other hand, in the period 2007-2015, improvements in mortality from IHD and diabetes led to increases in life expectancy among women and men in most states. The extent of subnational variation in the impact of homicides, IHD and diabetes-related mortality on life expectancy at birth, with a considerably high burden in Northern states, demonstrates the persistence of health inequalities in Brazil. ${ }^{32}$

Medically amenable mortality contributed significantly to increasing life expectancy throughout the period from 2000 to 2015. Although in two states, Acre and Maranhão, mortality from amenable causes of death deteriorated between 2000 and 2007, these states recovered and improved life expectancy by reducing mortality attributable to medically amenable causes in 2007-2015. Our results mirror findings reported in similar studies. Previous evidence suggests that improvements in primary healthcare have played an essential role in reducing deaths amenable to healthcare in Brazil. ${ }^{97}$ Similarly, our study highlights the importance of building a strong healthcare system in the Northern regions 
to further reduce IHD-related mortality. Comprehensive and community-based health interventions can contribute to further decrease mortality from IHD in areas with high prevalence through a combination of measures focused on prevention, healthcare and follow-up for heart diseases. ${ }^{25}$

\section{Strengths and limitations}

The analysis has several limitations. First, Brazilian mortality data were still considered 'incomplete' according to the Pan American Health Organization's criteria despite improvements in death counts coverage, particularly regarding certificate completeness and age reporting. ${ }^{48}$ To address this, we used death estimates corrected for completeness based on indirect demographic methods (see online supplemental appendix 1). ${ }^{26}$ Additionally, we used 5-year age groups to avoid age-heaping bias and applied death distribution methods in age groups with low rates of migration to minimise the effect of migration on our estimates. ${ }^{20}$ Second, causes of death could have been misclassified. To minimise chances of misclassification, we used broad cause of death categories that uses the concept of avoidable/amenable mortality and used data from 2000 onwards, using only the ICD-10 classification. In addition, some groups of causes are not consistent between states. For example, the group Y87 (deaths due to the sequelae of suicides and homicides) cannot be disaggregated for all the states in Brazil to attribute a share to homicides. The impact that this might have on our results, however, is negligible as deaths classified with this group represent only $0.009 \%$ of the total deaths. Finally, the concept of amenable mortality is not able to allude to differences in the effectiveness of healthcare interventions over time and between states. ${ }^{40}$ In addition, the Brazilian Ministry of Health restricts classification of causes amenable to medical services up to age 75 years, a common practice when classifying avoidable mortality ${ }^{50}$ To ensure comparability, we did not consider causes of death amenable to medical service above age 75 years.

\section{CONCLUSION AND FUTURE DIRECTIONS}

There is a need for increased attention and approaches to violence as a public health problem. During the health transition, the emphasis of healthcare shifted from acute to chronic care without incorporating violence as a dimension of healthcare. Latin America, including Brazil, is currently the region with the highest homicide rates globally. ${ }^{14}$ Homicide mortality in Latin American countries is strongly associated with political instability, economic inequality, social segregation and drug trafficking. We show that in Brazil there is a need for state-specific interventions to change the cultural, economic and social conditions associated with risk factors that trigger the surge of violence.

The gains made in reducing mortality attributable to causes amenable to medical services in Brazil are the primary driver of increases in life expectancy, however homicide mortality offsets this increase by over half a year in 12 states. This subnational heterogeneity within Brazil mirrors the diversity found across many Latin American countries. Homicide mortality is a local problem, however one that is a pertinent public health issue across the region, and which continues to inhibit progress towards longer and healthier lives. Better data collection is needed to accurately assess the effects of mortality from homicides on life expectancy by subpopulations, including within states.

\section{Author affiliations}

${ }^{1}$ Leverhulme Centre for Demographic Science, Department of Sociology and Nuffield College, University of Oxford, Oxford, UK

${ }^{2}$ Interdisciplinary Centre on Population Dynamics, University of Southern Denmark, Odense, Denmark

${ }^{3}$ CEDEPLAR, Universidade Federal de Minas Gerais, Belo Horizonte, Brazil ${ }^{4}$ Department of Public Health and Primary Care, University of Cambridge, Cambridge, UK

${ }^{5}$ School of Demography, Australian National University, Canberra, Australian Capital Territory, Australia

Twitter José Manuel Aburto @jm_aburto, Julia Calazans @_JuliaCalazans_and Bernardo Lanza Queiroz @blqueiroz

Contributors JMA, JC, BLQ, SL and VC-R contributed to the design of the study. JMA wrote the first draft of the manuscript that was revised by all authors. JMA, BLQ and JC performed the demographic and statistical analysis. All authors contributed to interpretation of data, revised the article critically for important intellectual content and approved the final version of the manuscript.

Funding JMA acknowledges support from the Newton International Fellowship and the Leverhulme Trust.

Map disclaimer The depiction of boundaries on the map(s) in this article does not imply the expression of any opinion whatsoever on the part of BMJ (or any member of its group) concerning the legal status of any country, territory, jurisdiction or area or of its authorities. The map(s) are provided without any warranty of any kind, either express or implied.

Competing interests None declared.

Patient consent for publication Not required.

Ethics approval This article used aggregated, fully anonymised, publicly available data. Therefore, no ethical approval is needed.

Provenance and peer review Not commissioned; externally peer reviewed.

Data availability statement Data are available in a public, open access repository. This analysis used publicly available data. All data and scripts are available at https://github.com/jmaburto/Homicides-and-life-expectancy-in-Brazil.

Supplemental material This content has been supplied by the author(s). It has not been vetted by BMJ Publishing Group Limited (BMJ) and may not have been peer-reviewed. Any opinions or recommendations discussed are solely those of the author(s) and are not endorsed by BMJ. BMJ disclaims all liability and responsibility arising from any reliance placed on the content. Where the content includes any translated material, BMJ does not warrant the accuracy and reliability of the translations (including but not limited to local regulations, clinical guidelines, terminology, drug names and drug dosages), and is not responsible for any error and/or omissions arising from translation and adaptation or otherwise.

Open access This is an open access article distributed in accordance with the Creative Commons Attribution Non Commercial (CC BY-NC 4.0) license, which permits others to distribute, remix, adapt, build upon this work non-commercially, and license their derivative works on different terms, provided the original work is properly cited, appropriate credit is given, any changes made indicated, and the use is non-commercial. See: http://creativecommons.org/licenses/by-nc/4.0/.

\section{ORCID iDs}

José Manuel Aburto http://orcid.org/0000-0002-2926-6879

Bernardo Lanza Queiroz http://orcid.org/0000-0002-2890-1025

Vladimir Canudas-Romo http://orcid.org/0000-0001-6532-0089

\section{REFERENCES}

1 Canudas-Romo V, Aburto JM. Youth lost to homicides: disparities in survival in Latin America and the Caribbean. BMJ Glob Health 2019;4:e001275. 
2 Malta DC, Minayo MCdeS, Soares Filho AM, et al. Mortalidade e anos de vida perdidos por violências interpessoais e autoprovocadas no Brasil e Estados: análise das estimativas do Estudo Carga Global de Doença, 1990 E 2015. Rev Bras Epidemiol 2017;20:142-56.

3 Reichenheim ME, de Souza ER, Moraes CL, et al. Violence and injuries in Brazil: the effect, progress made, and challenges ahead. The Lancet 2011;377:1962-75.

4 Guanais FC, Macinko J. The health effects of decentralizing primary care in Brazil. Health Aff 2009;28:1127-35.

5 Macinko J, Harris MJ. Brazil's family health strategy-delivering community-based primary care in a Universal health system. N Engl J Med Overseas Ed 2015;372:2177-81.

6 Paim J, Travassos C, Almeida C, et al. The Brazilian health system: history, advances, and challenges. The Lancet 2011;377:1778-97.

7 Victora CG, Barreto ML, do Carmo Leal M, et al. Health conditions and health-policy innovations in Brazil: the way forward. The Lancet 2011;377:2042-53.

8 United Nations. World population prospects: the 2017 revision. population division of the Department of economic and social affairs of the United nations Secretariat, New York. New York: United Nations, 2017.

9 Hone T, Rasella D, Barreto M, et al. Large reductions in amenable mortality associated with Brazil's primary care expansion and strong health governance. Health Aff 2017;36:149-58.

10 Macinko J, Dourado I, Aquino R, et al. Major expansion of primary care in Brazil linked to decline in unnecessary hospitalization. Health Aff 2010;29:2149-60.

11 Briceño-León R, Villaveces A, Concha-Eastman A. Understanding the uneven distribution of the incidence of homicide in Latin America. Int J Epidemiol 2008;37:751-7.

12 Borges GM. Health transition in Brazil: regional variations and divergence/convergence in mortality. Cad Saúde Pública 2017;33.

13 Iwakami Beltrão K, Dellasoppa EE. El designio de los hombres. Años de vida perdidos en Brasil y en sus grandes regiones, 1980 a 2005. Estudios demográficos y urbanos 2011;26:299-343.

14 United Nations Office on Drugs and Crime. Global study on homicide 2013: trends, contexts, data. United Nations 2014 https://doi.org/10. 18356/c1241a80-en

15 Ministry of Health in Brazil. DATASUS. Available: https://datasus. saude.gov.br/ [Accessed 6 February 2021].

16 Brazilian National Statistics Office. Population projections, 2017. Available: https://www.ibge.gov.br/estatisticas-novoportal/sociais/ populacao/9103-estimativas-de-populacao.html2017

17 Hill K. Estimating census and death registration completeness. Asian Pac Popul Forum 1987;1:8-13, 23-24.

18 Hill K, You D, Choi Y. Death distribution methods for estimating adult mortality: sensitivity analysis with simulated data errors. Demographic Research 2009;21:235-54.

19 Lima EECde, Queiroz BL. Evolution of the deaths registry system in Brazil: associations with changes in the mortality profile, underregistration of death counts, and ill-defined causes of death. Cad Saude Publica 2014;30:1721-30.

20 Queiroz BL, FHMdA F, Gonzaga MR. Completeness of death-count coverage and adult mortality (45q15) for Brazilian states from 1980 to 2010. Revista Brasileira de Epidemiologia 2017;20:21-33.

21 Nolte E, McKee M. Does health care save lives? Avoidable mortality revisited. London: The Nuffield Trust, 2004.

22 Aburto JM, Beltrán-Sánchez H, García-Guerrero VM, et al. Homicides in Mexico reversed life expectancy gains for men and slowed them for women, 2000-10. Health Aff 2016;35:88-95.

23 Malta DC, Sardinha L, Ld M. Atualização da lista de causas de mortes evitáveis por intervenções do Sistema Único de Saúde do Brasil. Epidemiologia e Serviços de Saúde 2010;19:173-6.

24 de Almeida-Pititto B, Dias ML, de Moraes ACF, et al. Type 2 diabetes in Brazil: epidemiology and management. Diabetes Metab Syndr Obes 2015;8:17.

25 Rasella D, Harhay MO, Pamponet ML, et al. Impact of primary health care on mortality from heart and cerebrovascular diseases in Brazil: a nationwide analysis of longitudinal data. BMJ 2014;349:g4014.

26 Botega NJ, LdSL G. Brazil: the need for violence (including suicide) prevention. World psychiatry 2004;3:157.

27 Macinko J, de Fátima Marinho de Souza M, Guanais FC, et al. Going to scale with community-based primary care: an analysis of the family health program and infant mortality in Brazil, 1999-2004. Soc Sci Med 2007:65:2070-80.

28 Preston S, Heuveline P, Guillot M. Demography: measuring and modeling population processes. Malden, MA: Blackwell Publishers, 2000.

29 Horiuchi S, Wilmoth JR, Pletcher SD. A decomposition method based on a model of continuous change. Demography 2008;45:785-801.

30 Team RC. R: A language and environment for statistical computing [Internet]. R Foundation for Statistical Computing, Vienna, Austria, 2013. Available: http://www r-project org

31 Consejo Ciudadano para la Segfuridad Pública y la Justicia Penal. Las 50 ciduades más violentas del mundo 2018 [The 50 most dangerous cities in the worl 2018]: Seguridad, Justicia y Paz, 2019. Available: http://www.seguridadjusticiaypaz.org.mx/seguridad/1567estudio-las-50-ciudades-mas-violentas-del-mundo-2018

32 Marinho F, de Azeredo Passos VM, Carvalho Malta D, Malta DC, et al. Burden of disease in Brazil, 1990-2016: a systematic subnational analysis for the global burden of disease study 2016. The Lancet 2018;392:760-75.

33 Marinho de Souza MdeF, Macinko J, Alencar AP, et al. Reductions in firearm-related mortality and hospitalizations in Brazil after gun control. Health Aff 2007;26:575-84.

34 Murray J, Cerqueira DRdeC, Kahn T. Crime and violence in Brazil: systematic review of time trends, prevalence rates and risk factors. Aggress Violent Behav 2013;18:471-83.

35 Cerqueira DR, RLd M. Vidas perdidas e racismo no Brasil, 2013. Available: https://bibliotecadigital.mdh.gov.br/jspui/handle/192/363

36 Souza G, Magalhães F, Gama I. Determinantes sociais E sua interferência nas taxas de homicídio em uma metrópole do Nordeste brasileiro. Rev Bras Epidemiol Suppl DSS 2014:194-203.

37 Waiselfisz JJ. Homicídio POR Armas de fogo no Brasil, 2016. Available: https://www.mapadaviolencia.net.br/ [Accessed 6 February 2021].

38 Wanzinack C, Signorelli MC, Reis C. Homicides and socioenvironmental determinants of health in Brazil: a systematic literature review. Cad. Saúde Pública 2018;34:e00012818.

39 Wanzinack C, Signorelli MC, Reis C. Homicides and socioenvironmental determinants of health in Brazil: a systematic literature review. Cadernos de Saúde Pública 2018;34:e00012818.

40 Canudas-Romo V, García-Guerrero VM, Echarri-Cánovas CJ. The stagnation of the Mexican male life expectancy in the first decade of the 21st century: the impact of homicides and diabetes mellitus. $J$ Epidemiol Community Health 2015;69:28-34.

41 González-Pérez GJ, Vega-López MG, Flores-Villavicencio ME. The increase of firearm mortality and its relationship with the stagnation of life expectancy in Mexico. Ciência \& Saúde Coletiva 2017;22:2861-72.

42 Aburto JM, Beltrán-Sánchez H. Upsurge of homicides and its impact on life expectancy and life span inequality in Mexico, 2005-2015. Am $J$ Public Health 2019:109:483-9.

43 García J, Aburto JM. The impact of violence on Venezuelan life expectancy and lifespan inequality. Int $J$ Epidemiol 2019;48:1593-601.

44 Dávila-Cervantes CA, Pardo-Montaño AM. Violence in Colombia and Mexico: trend and impact on life expectancy of homicide mortality between 1998 and 2015. Public Health 2018;163:1-8.

45 González-Pérez GJ, Vega-López MG, ERd S. Violence deaths and its impact on life expectancy: a comparison between Mexico and Brazil. Ciência \& Saúde Coletiva 2017;22:2797-809.

46 Canudas-Romo V, Aburto JM, García-Guerrero VM, et al. Mexico's epidemic of violence and its public health significance on average length of life. J Epidemiol Community Health 2017;71:188-93.

47 Alvarez J-A, Aburto JM, Canudas-Romo V. Latin American convergence and divergence towards the mortality profiles of developed countries. Population studies 2019:1-18.

48 Pan American Health Organization. Health situation in the Americas: basic indicators 2000, 2000. Available: https://iris.paho.org/handle/ $10665.2 / 45785$

49 Nolte E, McKee CM. Measuring the health of nations: updating an earlier analysis. Health Aff 2008;27:58-71.

50 Aburto JM, Riffe T, Canudas-Romo V. Trends in avoidable mortality over the life course in Mexico, 1990-2015: a cross-sectional demographic analysis. BMJ Open 2018;8:e022350. 